\title{
A STUDY OF NUTRIENT FORAMEN OF DRY ADULT HUMERUS BONES OF WEST BENGAL POPULATION
}

\author{
Ankana Saha *1, Madhumita Datta ${ }^{2}$, Soumya Chakraborty ${ }^{3}$, Sudipa Biswas ${ }^{4}$, \\ Suranjali Sharma ${ }^{5}$. \\ ${ }^{* 1}$ Demonstrator, Department of Anatomy, ESI-PGIMSR \& ESIC Medical College, Kolkata, India. \\ ${ }^{2}$ Demonstrator, Department of Anatomy, IPGME\&R, Kolkata, India. \\ ${ }^{3}$ Professor \& Head, Department of Anatomy, ESI-PGIMSR \& ESIC Medical College, Kolkata, India. \\ ${ }^{3}$ Associate Professor, Department of Anatomy, ESI-PGIMSR \& ESIC Medical College, Kolkata,India. \\ ${ }^{5}$ Assistant Professor, Department of Anatomy, ESI-PGIMSR \& ESIC Medical College, Kolkata, India.
}

\section{ABSTRACT}

Background: Nutrient foramen (NF) is an opening on the surface of bone which conduct peripheral nerve and nutrient artery. The major blood supply for long bones arise from this nutrient arteries. This supply is essential during the growing period and early phases of ossification and surgical interventions such as bone grafts, tumour resection, congenital pseudoarthrosis and in transplant techniques in Orthopaedics. This study was aimed to determine the number, direction, position of nutrient foramen and whether the nutrient foramina obey the general rule that is directed away from the growing end of the bone.

Materials and Methods: The present study involved a review of 80 dry humerus of adult population of West Bengal (WB) which were taken from Department of Anatomy, ESI-PGIMSR \& ESIC Medical College.

Results: $60 \%$ bones had single foramen while $30 \%$ bones had double foramen, and $5 \%$ bones had triple foramen $5 \%$ bones showed no foramen. Major nutrient foramina were directed distally i.e. towards elbow and $76.85 \% \mathrm{NF}$ were located on antero-medial surface of shaft and there were no change in the obliquity of the foramina.

Conclusion: Majority of the bones followed "Growing End Theory". This study recorded data related to WB population, providing comparable ethnic data which may help in surgical procedures and in the interpretation of radiological images.

KEY WORDS: Humerus, Nutrient foramina, Medullary cavity, West Bengal population.

Address for Correspondence: Dr. Ankana Saha, Demonstrator, Department of Anatomy. ESI-PGIMSR \& ESIC Medical College, Joka, Kolkata, India. E-Mail: ankana502@gmail.com

\begin{tabular}{|l|l|}
\hline \multicolumn{3}{|c|}{ Access this Article online } \\
\hline Quick Response code & Web site: International Journal of Anatomy and Research \\
ISSN 2321-4287 \\
www.ijmhr.org/ijar.htm
\end{tabular}

\section{INTRODUCTION}

Nutrient foramen is an opening on the surface bone which gives entrane to the blood vessels of the medullary cavity of a bone, for its nourishment and growth. The role of nutrient foramen in nutrition and growth of the bones is evident from term "nutrient" itself. The probable role of nutrient foramen in few cases 
of vascular necrosis is pointed out [1]. Knowledge of position of nutrient foramen can be useful in certain surgical procedures like bone grafting and more recently in microsurgical vascularized bone transplantation [2]. The nutrient artery is the principal source of blood supply to the long bone, and is particularly important during its active growth period in the embryo and fetus, as well as during the early phase of ossification [3]. Bones adapt to the mechanical environment and contain naturally occurring holes which allow blood vessels to pass through the bone cortex. These blood vessels are compromised especially in childhood due to medullary bone ischaemia with less vascularization of the metaphysis and growth plate [4].

It has been suggested that the direction of the nutrient foramen is determined by the growing end of the bone, which is supposed to grow at least twice as fast as the non-growing end. As a result, the nutrient vessels move away from the growing end of the bone [4]. As popularly stated they "seek the elbow and flee from the knee", showing their varying direction in both limbs. Only a few studies have reported variation in direction of the nutrient foramina in the upper limb bones [5]. Our aim was to determine the number, direction, location of nutrient foramen in dry humerus of adult population of West Bengal and whether the nutrient foramina obey the general rule that is, directed away from the growing end of the bone.

Rationale: The study of nutrient foramina is important in both morphological and clinical aspects. Some pathological bone conditions such as fractures healing or acute hematogenic osteomyelitis are closely related to the vascular system of the bone [6]. Detailed data on the blood supply to the long bones is invariably crucial in the development of new transplantation and resection techniques in Orthopaedics [2,7]. An understanding of the position and number of the nutrient foramina in long bones is important in Orthopaedic surgical procedures such as joint replacement therapy, fracture repair, bone grafts and vascularized bone microsurgery so that surgeons could avoid nutrient foramen during an open reduction to improve fracture healing [2].

\section{MATERIALS AND METHODS}

A study of 80 dry adult humerus 40 left and right sided each was undertaken. The samples were taken from the Department of Anatomy ESI-PGIMSR \& ESIC Medical College, Joka, Kolkata. The samples were intact, clean and dried humerus with no apparent visible pathological changes. The specific age and sex of the studied bones were unknown but bones were obtained from WB. In all these bones after determining the sides, the nutrient foramina were studied based on:

i. The number of foramina on the shaft of bone -80 humerus were studied, 40 left and 40 right sided, to determine number of nutrient foramina or whether there was any absence of foramen.

ii. Direction and obliquity of nutrient foramen A fine stiff unbreakable wire was used to confirm the direction and obliquity of the foramen.

iii. Determination of Total length of humerus (TL) - total length of individual humerus was taken as distance between superior point on the humeral head and the most distal point of medial projection of the trochlea of humerus. Length was measured by osteometric board.

iv. Surface on which nutrient foramina were located-Humerus were examined to know the position of nutrient foramen according to the antero-medial, posterior and antero-lateral surfaces.

v. Determination of foraminal index (FI) - foraminal index was calculated by the following formula.

F.I. $=$ (the distance from the proximal end of the bone to the nutrient foramen / total bone length) $\times 100[8,9]$

All measurements were taken to the nearest $0.1 \mathrm{~mm}$ using Vernier caliper [2]

vi. Location of nutrient foramina according to $\mathrm{FI}$ - Location of foramina was divided into three types according to $\mathrm{FI}$ as follows:

Type 1: FI below 33.33, the foramen was in the proximal third of the bone

Type 2: Fl from 33.33 upto 66.66, the foramen was in the middle third of the bone

Type 3: FI above 66.66, the foramen was in the distal third of the bone 
Instruments used for the study:

1. Hand lens- used to locate nutrient foramen

2. Osteometric board- used to measure the length of long bones

3. Vernier calipers both curved and straight- used to measure distance of nutrient foramen from end of the bones

Nutrient foramina were identified by their elevated margins and by the presence of a distinct groove proximal to them. Only welldefined foramina on the diaphysis were accepted. Foramina at the ends of the bones were ignored.

Data analysis: Data are expressed as means and standard deviation for continuous variables, and percentage for categorical variables.

\section{RESULTS}

Number of nutrient foramina: Out of 80 humerus (40 of left side and 40 of right side), 48 humerus had single foramen i.e. $60 \%$ (22 left side and 26 right side), 24 had double foramina i.e. $30 \%$ (14 of left and 10 of right side). 4 humerus had triple foramina and 4 humerus had no foramen i.e. $5 \%$ of each of total humerus studied (Table 1) All the foramina except one were directed away from the growing end.

Table 1: Number of nutrient foramina of humerus with percentages.

\begin{tabular}{|c|c|c|c|}
\hline $\begin{array}{c}\text { No.of } \\
\text { foramina }\end{array}$ & $\begin{array}{c}\text { No. of left } \\
\text { humerus (\%) } \\
(n=80)\end{array}$ & $\begin{array}{c}\text { No. of right } \\
\text { humerus (\%) } \\
(n=80)\end{array}$ & $\begin{array}{c}\text { Total no. of } \\
\text { bones (\%) } \\
(n=80)\end{array}$ \\
\hline 1 & $22(55 \%)$ & $26(65 \%)$ & $48(60 \%)$ \\
\hline 2 & $14(35 \%)$ & $10(25 \%)$ & $24(30 \%)$ \\
\hline 3 & $2(5 \%)$ & $2(5 \%)$ & $4(5 \%)$ \\
\hline 0 & $2(5 \%)$ & $2(5 \%)$ & $4(5 \%)$ \\
\hline
\end{tabular}

Direction and obliquity of nutrient foramina:

All the foramina were directed distally and there were no change in obliquity of the foramina.

Determination of total length of humerus: Total length of humerus measured ranged between $27.72 \mathrm{~cm}$ and $33.60 \mathrm{~cm}$, average \pm standard deviation were $30.81 \pm 1.71$ (table-2)

Table 2: Range, Mean \pm Standard deviation (SD) of total length of humerus.

\begin{tabular}{|c|c|c|c|}
\hline & Left & Right & Total \\
\hline Range & $27.72-33.60$ & $28.28-33.10$ & $27.72-33.60$ \\
\hline Average \pm SD & $30.81 \pm 1.71$ & $31.12 \pm 1.56$ & $30.81 \pm 1.71$ \\
\hline
\end{tabular}

Surface on which nutrient foramen were located- maximum number, 83 ( 45 left sided and 38 right sided) out of 108 nutrient foramina (76.85\%) were located on antero-medial surface of shaft of humerus. Small number of nutrient foramen 16 ( 8 humerus of each side) were situated in antero-lateral surface i.e. $14.81 \%$. Two NF had on middle of posterior surface, three $\mathrm{NF}$ had on posterior surface close to medial border and four NF had on posterior surface close to the lateral border (Table - 3)

Table 3: Horizontal position (surface) of nutrient foramen in shaft of humerus.

\begin{tabular}{|c|c|c|c|}
\hline \multirow[b]{2}{*}{ Position } & \multicolumn{2}{|c|}{ No. of NF (\%) } & \multirow{2}{*}{$\begin{array}{c}\text { Total no of } \\
\text { NF (\%) } \\
(n=108)\end{array}$} \\
\hline & $\begin{array}{l}\text { LEFT SIDE } \\
\qquad(n=56)\end{array}$ & $\begin{array}{l}\text { RIGHT SIDE } \\
\quad(n=52)\end{array}$ & \\
\hline Antero-medial surface & $45(80.36 \%)$ & $38(73.08 \%)$ & $83(76.85 \%)$ \\
\hline $\begin{array}{l}\text { Posterior surface (in the } \\
\text { middle of surface) }\end{array}$ & $1(1.79 \%)$ & $1(1.92 \%)$ & $2(1.85 \%)$ \\
\hline $\begin{array}{l}\text { Posterior surface (close to } \\
\text { medial border) }\end{array}$ & $1(1.79 \%)$ & $2(3.85 \%)$ & $3(2.78 \%)$ \\
\hline $\begin{array}{l}\text { Posterior surface (close to } \\
\text { lateral border) }\end{array}$ & $1(1.79 \%)$ & $3(5.77 \%)$ & $4(3.70 \%)$ \\
\hline Antero-lateral surface & $8(14.28 \%)$ & $8(15.38 \%)$ & $16(14.81 \%)$ \\
\hline
\end{tabular}

Determination of foraminal index (FI): Foraminal Index ranged from 38.22 to 70.39 and average \pm standard deviation ranged from $56.23 \pm 9.83$ to $57.59 \pm 10.45$ (Table- 4)

Table 4: Range and Mean \pm Standard deviation Foraminal Index (FI).

\begin{tabular}{|c|c|c|c|c|}
\hline \multirow{2}{*}{ LOCATION } & \multicolumn{2}{|c|}{ RANGE } & \multicolumn{2}{c|}{ MEAN \pm SD } \\
\cline { 2 - 5 } & Left & Right & Left & Right \\
\hline Antero-medial surface & $40.45-64.65$ & $53.62-70.39$ & $52.55 \pm 3.12$ & $62.00 \pm 1.52$ \\
\hline Posterior surface & $41.67-52.14$ & $38.22-57.99$ & $46.91 \pm 8.29$ & $48.11 \pm 6.72$ \\
\hline Antero-lateral surface & $57.14-67.85$ & $43.83-53.21$ & $62.50 \pm 2.14$ & 48.525 .44 \\
\hline
\end{tabular}

Table 5: Position \& direction of nutrient foramen of humerus.

\begin{tabular}{|c|c|c|c|c|l|}
\hline \multirow{2}{*}{ Side } & \multirow{2}{*}{$\begin{array}{c}\text { Total No. of } \\
\text { foramen }\end{array}$} & \multicolumn{3}{|c|}{ Position } & \multirow{2}{*}{ Direction } \\
\cline { 3 - 5 } & Type1 & Type2 & Type3 & \\
\hline Left & 56 & - & $44(78.57 \%)$ & $12(21.43 \%)$ & Distally \\
\hline Right & 52 & - & $45(86.54 \%)$ & $7(13.46 \%)$ & Distally \\
\hline Total & 108 & - & $89(82.41 \%)$ & $19(17.59 \%)$ & Distally \\
\hline
\end{tabular}

Location of the nutrient foramen according to FI: most of the nutrient foramen (82.41\%) were situated on middle one third of the shaft of humerus i.e. 44 nutrient foramen of left 
humerus which consisted of $78.57 \%$ of total humerus and 45 nutrient foramen of right humerus whose percentage was $86.54 \%$. Only $19 \mathrm{NF}$ was found on distal one third which composed of $17.59 \%$ out of which 12 of left side and 7 of right side. Not a single nutrient foramen was located on the proximal one third of the shaft of humerus (Table 5).

\section{DISCUSSION}

The arrangement of diaphyseal nutrient foramen in long bones usually follows a definite pattern. Nutrient foramen is mostly found in flexor aspect and they are more or less around a fixed area, but the exact spot varied considerably.

The direction of nutrient foramina in human long bones is directed away from the growing end that is directed towards elbow in upper limbs while in lower limb it is directed away from knee. This is due to one end of long bone is growing faster than the other end. Variation in direction of nutrient foramen have been observed in many tetrapods but there is some similarity in the nutrient foraminal pattern in birds and mammals (Hughes 1952) [8]. This theory fails to explain the abnormal direction of foramina.

The foramen may be a potential area of weakness and allow development of a fracture due to increased physical activity or low quality of the bone. These stress fractures can be diagnosed by their position relative to the nutrient foramen and the patterns of edema [10].

In the present study, a single nutrient foramen had a higher percentage (60\%) in the humeral bones, compared to that of double foramina (30\%) and triple foramina (5\%). Carroll SE [11] in 1963, Forriol Campos et al [4] in 1987 and Mysorekar VR [12] in 1967 reported almost 60\% single nutrient foramen similar to that of the present result, though Kizilkanat et al [3] in 2007 showed single foramen in $88 \%$. The range of occurrence of double foramina was found by Longia GS et al [5] in 1980 (13\%), Kizilkanat et al [3] in 2007 (22\%), Kumar S et al [13] in 2012 (26\%) and Mysorekar VR [12] in 1967 (42\%) which bears similarity with present study result. Kizilkanat et al [3] in 2007 found triple foramen in 7\% Humerus. Also, Malukar O [2] in 2011 and Kizilkanat et al [3] in 2007 in (2\%) reported the absence of nutrient foramina in some humerus.
They stated that in such cases, the periosteal vessels were entirely responsible for the blood supply of the bone. This is in accordance to the report of this present study as $5 \%$ humerus observed were without nutrient foramen. (Tab.1)

In the study $88 \%$ of the nutrient foramen were located along the middle 3rd of the humerus (Table 3). Mansur DI at al [14] in 2016 observed $94.84 \%$ foramen in middle third of humerus, Forriol Campos et al [4] in 1987 found most diaphysial nutrient foramen in middle third of the bones. Mysorekar VR [12] in 1967 showed $95 \%$ of foramen were situated in middle third out of 180 humerus. In contrast to the present study result, Malukar O [2] in 2011 reported 65\% of nutrient foramen in the middle third of humerus. In our present study, $84 \%$ of all humeral nutrient foramina were observed on the antero-medial surface of the bone (Table 4). Similar findings had been reported by Kizilkanat et al [3] in 2007 and Kumar et al [13] in 2012. Mansur DI at al [14] in 2016 concluded that the majority (88.86\%) of nutrient foramina were present on the antero-medial surface which is in line with present study result.

In this study, all the nutrient foramina in humerus were directed distally towards the elbow (away from the growing ends) (Table 3). Longia GS et al [5] in 1980 and Mansur DI et al [14] in 2016 observed all nutrient foramen directed distally. The study of Kumar et al [13] in 2012 showed variation in direction of NF in humerus.

\section{CONCLUSION}

We can thus conclude from present study that, out of 80 humerus studied, 48 i.e. $60 \%$ had single foramen, 24 i.e. $30 \%$ had double foramen, 4 i.e. $5 \%$ had triple foramina and 4 i.e. $5 \%$ had no foramen.

The study therefore confirmed previous reports regarding the number, position and direction of the nutrient foramina in the humerus. It also provided important information to the clinical significance of the nutrient foramina.

Accordingly, a well understanding of the characteristic morphological features of the nutrient foramen by orthopaedic surgeon is recommended. Exact position \& distribution of the nutrient foramina in bone diaphysis is 
important to avoid damage to the nutrient vessels during surgical procedures.

\section{ACKNOWLEDGEMENTS}

Authors acknowledge the great help received from the scholars whose article cited and included in references of this manuscript. The authors are sincerely thankful to all faculty members and staffs for extending their support in this study of our department of Anatomy, ESI- PGIMSR \& ESIC Medical College.

\section{Conflicts of Interests: None}

\section{REFERENCES}

[1]. Fraizer, Ernest J. The Anatomy of Human Skeleton $4^{\text {th }}$ Edition (1964).p5

[2]. Malukar O, Joshi H. Diaphysial Nutrient Foramina In Long Bones And Miniature Long Bones. NJIRM 2011;2(2):23-26.

[3]. Kizilkanat E, Boyan N, Ozsahin ET, Soames R \&Oguz $O$. Location, number and clinical significance of nutrient foramina in human long bones. Ann. Anat 2007;189:87-95.

[4]. Forriol Campos F, Gomez Pellico L, Gianonatti Alias M, Fernandez-Valencia R. A study of the nutrient foramina in human long bones. Surg. Radiol. Anat. 1987;9:251-255.

[5]. Longia GS, Ajmani ML, Saxena SK, Thomas RJ. Study of diaphyseal nutrient foramina in human long bones.Acta Anat. (Basel) 1980;107:399-406.

[6]. Skawina A, Wyczolkowski M. Nutrient foramina of humerus, radius and ulna in Human Fetuses. Folia Morphol. 1987;46:17-24.
[7]. Kirschner MH, Menck J, Hennerbichler A, Gaber O \& Hofmann GO. Importance of arterial blood supply to the femur and tibia transplantation of vascularized femoral diaphyseal and knee joints. World J. Surg 1998;22:845-52.

[8]. Hughes $\mathrm{H}$. The factors determining the direction of the canal for the nutrient artery in the long bones of mammals and birds. Acta Anat. 1952;15:261-80.

[9]. Shulman SS. Observations of the nutrient foramina of the human radius and ulna. Anat. Rec. 1959;134:685-97.

[10]. Craig JG, Widman D, Van Holsbeeck M. Longitudinal stress fracture: patterns of edema and the importance of the nutrient foramen. Skeletal Radiol. 2003; 32: 22-27

[11]. Carroll SE. A study of the nutrient foramina of the humeral diaphysis. J. Bone Jt. Surg. 1963;45:176181.

[12]. Mysorekar VR. Diaphysial nutrient foramina in human long bones. J Anat. 1967;101:813-822.

[13]. Kumar S, Kathiresan K, Gowda MST, Nagalaxmi. Study of Diaphysial Nutrient Foramina In Human Long Bones. Anatomica Karnataka 2012;6(2):66-70.

[14]. Mansur DI, Manandhar P, Haque MK, Mehta DK, Duwal S, Timalsina B. A study on variations of nutrient foramen of humerus with its clinical implications. Kathmandu Univ Med J 2016;53(1):78-83.

How to cite this article:

Ankana Saha, Madhumita Datta, Soumya Chakraborty, Sudipa Biswas, Suranjali Sharma. A STUDY OF NUTRIENT FORAMEN OF DRY ADULT HUMERUS BONES OF WEST BENGAL POPULATION. Int J Anat Res 2017;5(2.1):3722-3726. DOI: 10.16965/ijar.2017.157 